\title{
SISTEM INFORMASI JADWAL PENERBANGAN PESAWAT BERBASIS WEB PADA CV. DIRGA ADI DHARMA
}

\author{
Hari Purwanto \\ hari_1271@yahoo.co.id
}

\begin{abstract}
ion
In modern times at the present time, the development of airplane flight schedules in the world is growing rapidly. This can be seen with the increasing number of airplane schedules in the world using the website as a tool to view the flight departure schedule information and scheduled flight arrives. And the flight schedule of this online flight gets a lot of attention from the public who see the information through the flight schedule of the aircraft online.

Many passengers have to come to the airport just to see the flight schedule, even sometimes there is no renewal schedule from the airport. This of course carries the impact of loss because the time spent on seeing information can be more effective.

The authors hope with the existence of this information system, providing convenience for airplane passengers to monitor the schedule.

Keywords: schedule, information, system, flight
\end{abstract}

\section{PENDAHULUAN}

Perkembangan teknologi dan komunikasi saat ini begitu pesat, seiring dengan pesatnya laju perkembangan ini dituntut adanya informasi yang cepat, tepat dan akurat sehingga mengakibatkan persaingan yang semakin kompetitif. Ketatnya persaingan dan pesatnya perkembangan teknologi dan informasi yang ada menuntut suatu sistem yang lebih baik, cepat dan handal dalam menyelesaikan masalah.

Keinginan masyarakat untuk memperoleh kemudahan dalam melakukan kegiatan sehari hari mendorong pesatnya kemajuan teknologi. Banyak teknologi yang ditujukan untuk memberikan kemudahan yang diinginkan, seperti misalnya internet. Fakta yang tidak bisa ditolak saat ini adalah kenyataan hampir segala hal dapat diperoleh diinternet. Dengan kemajuan teknologi internet memungkinkan seseorang untuk memperoleh informasi dan melakukan transaksi dengan bebas tanpa dibatasi oleh ruang dan waktu.

Meskipun demikian, teknologi ini masih belum dimanfaatkan sepenuhnya. Adapun salah satu masalah yang menarik perhatian penulis adalah masalah yang cukup sederhana namun sering terjadi dalam kehidupan sehari-hari yaitu penjadwalan penerbangan pesawat. Salah satu alternatif penyelesaian masalah tersebut adalah dengan memanfaatkan internet baik melalui web di kantor, di warnet, di lingkungan sekolah, ataupun di rumah. Pelanggan dapat melihat informasi jadwal penerbangan pesawat kapanpun dan dimanapun secara online tanpa harus datang ke bandara.

Berdasarkan latar belakang diatas, dapat diidentifikasikan permasalahan yang ada yaitu sistem informasi yang ada saat ini belum menyediakan layanan informasi jadwal penerbangan secara online yang bisa dilihat kapanpun dan dimanapun.

Dalam penelitian ini penulis dapat merumuskan permasalahan- permasalahan yang terjadi bagaimana merancang sistem informasi jadwal penerbangan pesawat pada CV. Dirga Adi Dharma. Adapun tujuan penelitian yang di lakukan oleh penulis adalah merancang sistem informasi jadwal penerbangan peasawat berbasis webpada CV. Dirga Adi Dharma.

\section{LANDASAN TEORI}

\subsection{Pengertian Sistem}

Suatu sistem dapat diartikan sebagai suatu kumpulan atau himpunan dari unsur, komponen atau variabel-variabel yang terorganisir, saling berinteraksi, saling ketergantungan satu sama lain dan terpadu. Suatu sistem pada dasarnya adalah sekelompok unsur yang erat hubungannya satu dengan yang lain, yang berfungsi bersama-sama untuk mencapai tujuan tertentu.

Sistem menurut (Ais Zakiyudin, 2011: 5), "Sistem adalah setiap kesatuan secara konseptual atau fisik yang terdiri dari bagian-bagian yang saling mempengaruhi".

Secara umum sistem dapat didefinisikan sebagai suatu kumpulan secara konseptual yang saling berhubungan dan berinteraksi dalam suatu 
kesatuan yang saling mempengaruhi untuk suatu tujuan. Unsur-unsur suatu sistem terdiri dari subsistem yang lebih kecil, yang terdiri pula dari kelompok-kelompok unsur yang membentuk subsistem tersebut. Unsur-unsur sistem berhubungan erat satu sama lain dimana sifat serta kerja sama antar unsur dalam sistem tersebut mempunyai bentuk tertentu.

\subsection{Pengertian Sistem Informasi}

Menurut Bonnie Soeherman dan Marion Pinontoan "Sistem informasi merupakan serangkaian komponen berupa manusia, prosedur, data, dan teknologi (seperti komputer) yang digunakan untuk melakukan sebuah proses untuk menghasilkan informasi yang bernilai untuk pengambilan keputusan.

Sistem informasi dapat didefinisikan sebagai suatu sistem di dalam suatu organisasi yang merupakan kombinasi dari orang-orang, fasilitas, teknologi, media, prosedur-prosedur dan pengendalian yang ditujukan untuk mendapat jalur komunikasi penting, memproses tipe transaksi rutin tertentu, memberi sinyal kepada manajemen dan yang lainnya terhadap kejadiankejadian internal dan eksternal yang penting dan menyediakan suatu dasar informasi untuk pengambilan keputusan yang cerdik.

\subsection{UML (Unified Modelling Language)}

Unified Modelling Language (UML) adalah bahasa standar yang digunakan untuk menjelaskan dan memvisualisasikan arti dari proses analisis dan desain berorientasi objek.

Dalam bukunya Munawar menjelaskan bahwa "UML (Unified Modelling Language) sebagai salah satu alat bantu yang sering digunakan di dunia pengembangan sistem yang berorientasi obyek. Hal ini disebabkan karena UML menyediakan bahasa pemodelan visual yang memungkinkan bagi pengembang sistem untuk membuat cetak biru atas visi mereka dalam bentuk yang baku, mudah dimengerti serta dilengkapi dengan mekanisme yang efektif untuk berbagi (Sharing) dan mengkomunikasikan rancangan mereka dengan yang lain."

Abstraksi konsep dasar UML terdiri dari Structural Classification, Dynamic Behaviour dan Model Management. UML mendefinisikan Diagram - Diagram sebagai berikut :

\subsubsection{Use Case Diagram}

Use Case Diagram menggambarkan fungsionalitas yang diharapkan dari sebuah sistem. Yang ditekankan adalah "apa" yang diperbuat sistem, dan bukan "bagaimana". Sebuah Use Case mempresentasikan sebuah interaksi antara aktor dengan sistem. Use Case merupakan sebuah pekerjaan tertentu, misalnya login ke sistem, meng-Create sebuah daftar belanja, dan sebagainya. Seorang/sebuah aktor adalah sebuah entitas manusia atau mesin yang berinteraksi dengan sistem untuk melakukan pekerjaanpekerjaan tertentu. Use Case Diagram dapat sangat membantu bila kita sedang menyusun Requirement sebuah sistem, mengkomunikasikan rancangan dengan klien, dan merancang Test Case untuk semua Feature yang ada pada sistem.

\subsubsection{Class Diagram}

Class adalah spesifikasi yang jika diinstansiasi akan menghasilkan sebuah objek dan merupakan inti dari pengembangan dan desain berorientasi objek. Class menggambarkan keadaan (atribut/properti) suatu sistem, sekaligus menawarkan layanan untuk memanipulasi keadaan tersebut (metoda/fungsi).

\subsubsection{Statechart Diagram}

Statechart Diagram menggambarkan transisi dan perubahan keadaan (dari satu ke State lainnya) suatu objek pada sistem sebagai akibat dari stimuli yang diterima. Statechart Diagram bertugas menelusuri individu-individu objek tersebut melalui keseluruhan daur hidupnya, menspesifikasikan secara urutan yang mungkin dari pesan-pesan yang akan di terima oleh objek tersebut bersama atas tanggapan atas pesan-pesan tersebut. Statechart Diagram menyediakan variasi simbol dan sejumlah ide untuk pemodelan. Tipe Diagram ini mempunyai potensi untuk menjadi sangat kompleks dan dalam waktu yang sangat singkat.

\subsubsection{Activity Diagram}

Activity Diagram menggambarkan berbagai alir aktivitas dalam sistem yang sedang dirancang, bagaimana masing-masing alir berawal, decision yang mungkin terjadi, dan bagaimana mereka berakhir. Activity Diagram juga dapat menggambarkan proses paralel yang mungkin terjadi pada beberapa eksekusi.

\subsubsection{Sequence Diagram}

Sequence diagram menggambarkan interaksi antar objek di dalam dan di sekitar sistem (termasuk pengguna, Display, dan sebagainya) berupa Message yang digambarkan terhadap waktu. Sequence Diagram terdiri atas dimensi 
vertikal (waktu) dan dimensi horizontal (objekobjek yang terkait).

\subsubsection{Collaboration Diagram}

Collaboration diagram adalah bentuk lain Sequence Diagram. Bila sequece diagram diorganisir menurut waktu maka collaboration diagram diorganisir menurut ruang/space. Collaboration diagram merupakan asosiasi diantara obyek-obyek. Panah di dekat garis asosiasi menunjukkan message, sedangkan content message ditunjukkan dengan label. Angka pada message menunjukkan urutan message.

Dengan collaboration diagram memungkinkan untuk memodelkan pengiriman sebuah message ke banyak obyek pada class yang sama. Demikian juga halnya untuk menunjukkan adanya obyek aktif yang mengendalikan aliran dari message.

\subsubsection{Component Diagram}

Component Diagram mempresentasikan dunia riil item yaitu component software. Component software menetap di komputer bukan di benak para analis.

Componen Diagram menggambarkan struktur dan hubungan antar komponen piranti lunak, termasuk ketergantungan (dependency) diantaranya. Komponen piranti lunak adalah modul berisi code, baik berisi source code maupun binary code, baik library maupun executable, baik yang muncul pada compile time, link time, maupun run time.

\subsubsection{Deployment Diagram}

Deployment diagram atau physical diagram menggambarkan detail bagaimana komponen ditempatkan dalam pra struktur sistem, dimana komponen akan terletak (pada mesin server atau piranti keras apa), bagaimana kemampuan jaringan pada lokasi tersebut, spesifikasi server dan hal-hal lain yang bersifat fisikal. Sebuah node adalah server, work station atau piranti keras lain yang digunakan untuk menempatkan komponen dalam lingkungan yang sebenarnya.

\subsubsection{Package Diagram}

Merupakan sebuah bentuk pengelompokkan yang memungkinkan untuk mengambil sebuah bentuk UML dan mengelompokkan elemen-elemennya dalam tingkatan untuk yang lebih tinggi. Kegunaan package umumnya adalah mengelompokkan class.

\section{ANALISA SISTEM BERJALAN}

3.1 Prosedur Sistem Berjalan

Pada lokasi penelitian, yaitu CV. Dirga

Adi Dharma. Dibawah ini merupakan penjelasan dari gambaran keadaan sistem yang aktif digunakan.

1. Alur dimulai saat petugas bagian admin mengecek informasi jadwal penerbangan pesawat yang telah tersedia menggunakan JOH (Jadwal Operasional Harian).

2. Jika informasi jadwal penerbangan pesawat cukup dan dirasa tidak membutuhkan pembaharuan informasi maka operasional manager mengarsip JOH kembali, namun jika informasi jadwal penerbangan pesawat belum diperbaharui maka petugas bagian admin mengisi FPJ (Form Pengisian Jadwal) 2 rangkap.

3. Setelah itu FPB diberikan kepada direktur guna meminta persetujuan, jika direktur tidak menyetujui, FPB diberikan kembali kepada petugas bagian adminguna merevisi informasi jadwal penerbangan mana saja yang perlu dipebaharui atau tidak..

4. Namun jika disetujui oleh direktur kemudian direktur menadatangani FPB tersebut, lalu FPB diserahkan kepada operasional manager guna diberikan ke bagian admin yang kemudian langsung memperbaharui informasi jadwal penerbangan pesawat.

\subsection{Analisa Prosedur}

Berdasarkan prosedur sistem diatas dapat dideskripsikn perosedur kerja dari sistem informasi jadwal penerbangan pesawat pada CV. Dirga Adi Dharma adalah sebagai berikut:

\subsubsection{Prosedur Informasi}

Pelanggan datang ke bagian admin untuk mengetahui informasi jadwal penerbangan pesawat, jika pelanggan dari luar kota cukup menelpon dengan caramenanyakan informasi jadwal penerbangan pesawat mulai dari tujuan kota awal keberangkatan dan kota yang akan dituju, kemudian bagian admin mengecek informasi jadwal penerbangan pesawat, jika tidak ada informasi yang pelanggan inginkan bagian admin akan memberitahu pelanggan tetapi jika informasi yang pelanggan inginkan ada maka bagian admin langsung memberikan informasi yang ditanyakan oleh pelanggan. 


\subsubsection{Prosedur Konfirmasi}

Kemudian pelanggan mengetahaui informasi jadwal penerbangan pesawat tersebut, jenis informasi yang disampaiakan sesuai permintaan informasi dari pelanggan. dan bagian admin membuat laporan tentang adanya permintaan informasi yang telah pelanggan minta untuk mengetahui informasi jadwal penerbangan pesawat.

\subsubsection{Prosedur Laporan}

Untuk pelaporan bagian admin merekap hasil pertanyaan informasi jadwal penerbangan pesawat hariannya ke bagian operasional manager dan bagian operasional manager merekap hasil pertanyaan setiap bulan nya.

\section{PERANCANGAN SISTEM}

\subsection{Perancangan Sistem Informasi}

Perbaikan sistem dilakukan bila sistem baru telah berjalan dengan baik dan dapat menggantikan sistem lama. Cara pengalihan sistem yang digunakan adalah dengan cara program berbasis web yang diusulkan peneliti dioperasikan bersama-sama dengan sistem lama satu periode waktu terttentu. Kedua sistem ini diopersikan bersama-sama untuk meyakinkan bahwa sistem baru dapat beroperasi dengan baik sebelum sistem lama dihentikan. Hal ini dilakukan dengan tujuan agar:

1. Informasi yang dihasilkan oleh sistem lama masih tetap diperolah selama sistem yang baru belum dapat menghasilkan informasi yang dibutuhkan.

2. Dapat dilakukan perbandingan antara sistem yang lama dengan sistem yang baru. Sistem yang lama tetap digunakan jika ada kekurangan yang harus diperbaiki selama perbaikan sistem.

3. Agar bagian administrasi tidak mendapatkan kesulitan saat ingin membuat pembaharuan informasi jadwal penerbangan pesawat, sehingga memberikan kemudahan dalam pembuatan laporan.

\subsection{Perancangan Sistem usulan}

4.2.1 Prosedur

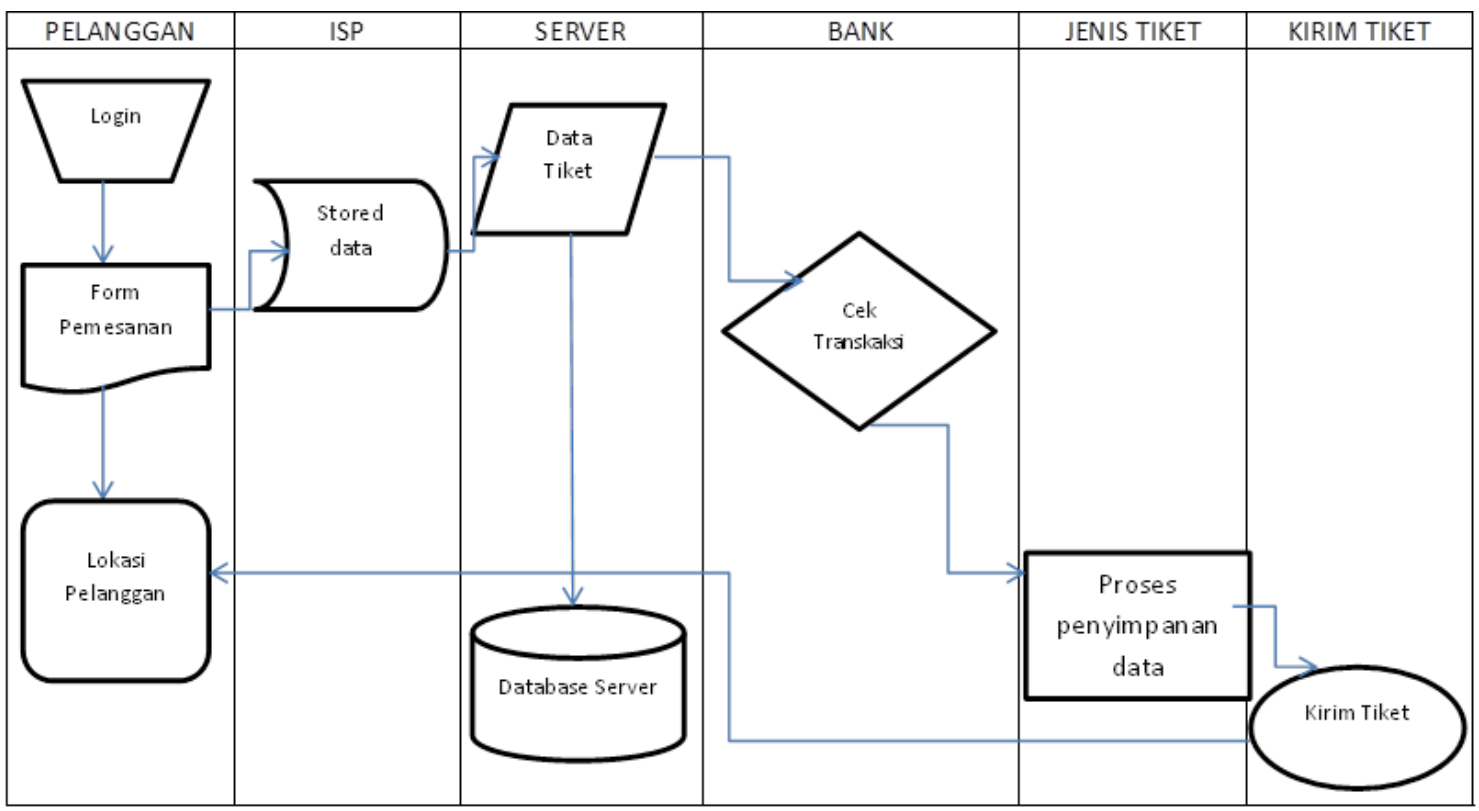

Gambar 4.1 Diagram Alir Proses Pemesanan

\section{Penjelasan :}

1. Pelanggan memesan tiket di website dengan mengisi order form yang ada.

2. Data pemesan dikirim oleh ISP ke server. Setelah diterima, disimpan di database server.
3. CV. Dirga Adi Dharma akan memeriksa account dibank apakah transaksi sesuai dan pelanggan telah mentransfer uang untuk memesan tiket melalui internet payment network. 
4. Selanjutntya, tiket yang dipesan akan dikirimkan ke alamat pelanggan yang sesuai di form pemesanan (order form).

\subsection{Prosedur Sistem Usulan}

Dalam rancangan sistem ini penulis menggunakan sistem pemodelan UML (Unified Modeling Language), dan digambarkan melalui diagram Use Case Diagram, Class Diagram, Activity Diagram, dan Sequence Diagram.

\subsubsection{UML (Unified Modeling Language) \\ 4.3.1.1 Diagram Use Case}

Use case diagram ini menggambarkan apa saja aktifitas yang dilakukan oleh sistem dari sudut pandang pengamatan dari luar. Adapun Rancangan Use Case Diagram yang diusulkan adalah sebagai berikut :

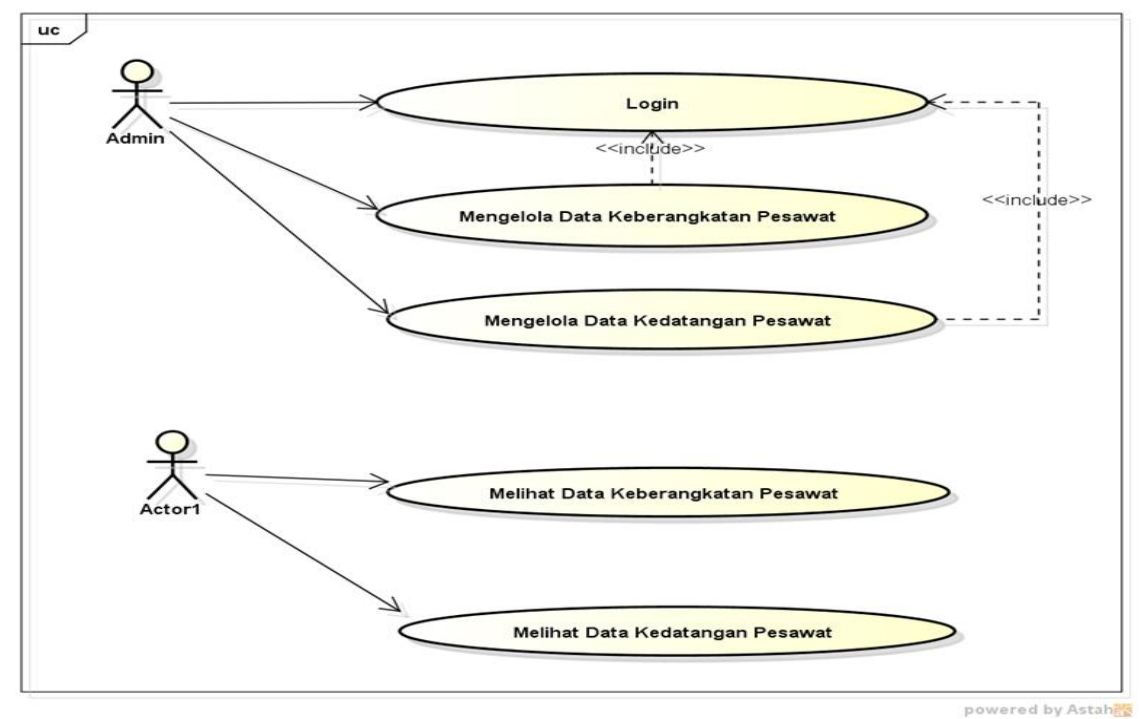

Gambar 4.3.1.1 Diagram Use Case

Keterangan: Di dalam use cae ini terdapat 1 aktor yang berperan di dalamnya. Garis yang mempunyai keterangan <<include>> merupakan sebuah use case yang bersifat opsional atau bisa diakses juga bisa tidak.. Use case sebelumnya harus di eksekusi terlebih dahulu sebelum dapat mengakses use case tersebut.

\subsubsection{Activity Diagram \\ 4.3.1.2.1 Diagram Aktivity User}

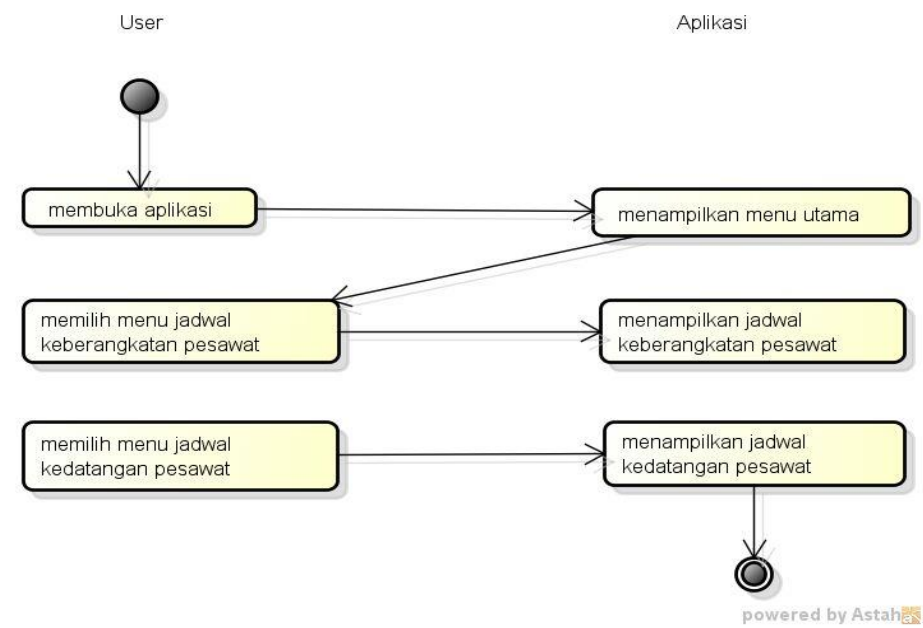

Gambar 4.3.1.2.1 Diagram Aktivity User 


\subsection{Diagram Aktivity Login}

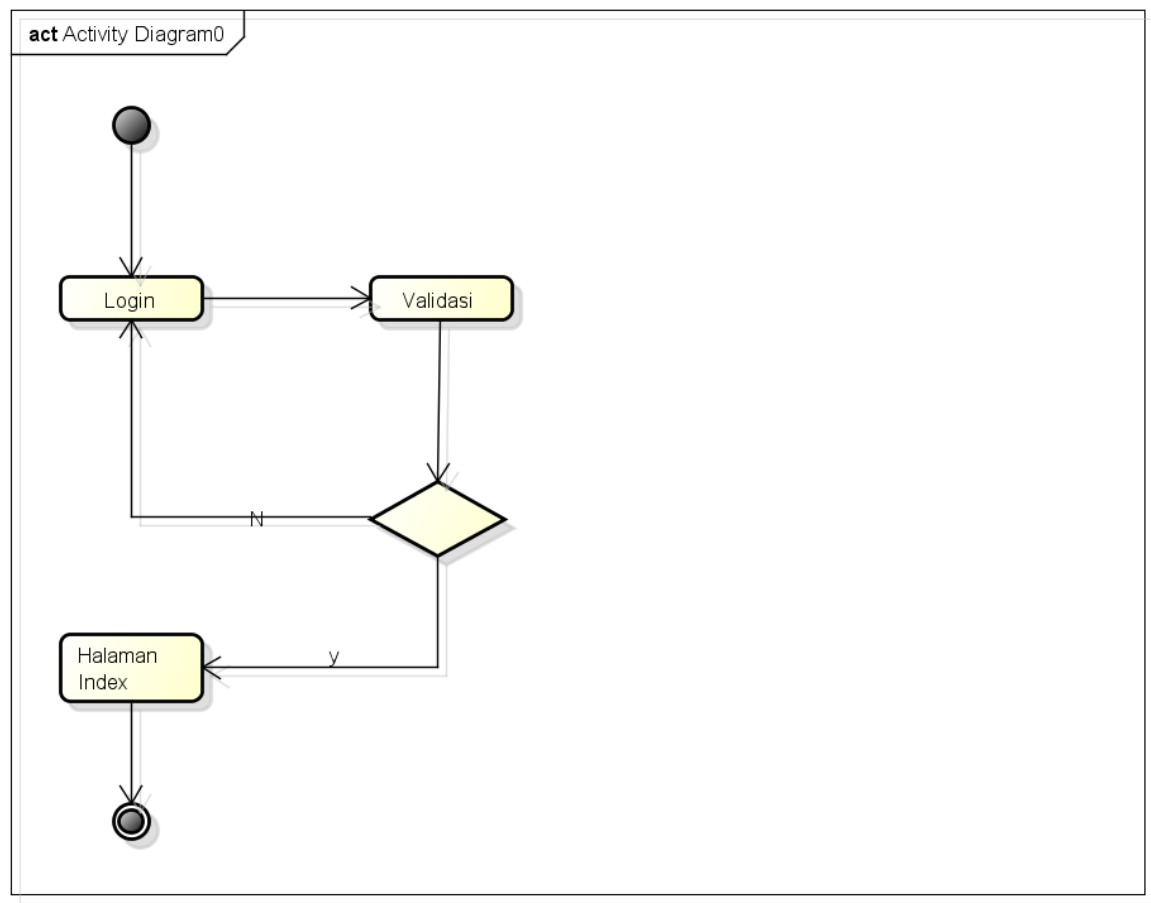

powered by Astahä

Gambar 4.3.1.2.2 Diagram Aktivity Login

\subsection{Diagram Activity Cek Jadwal}

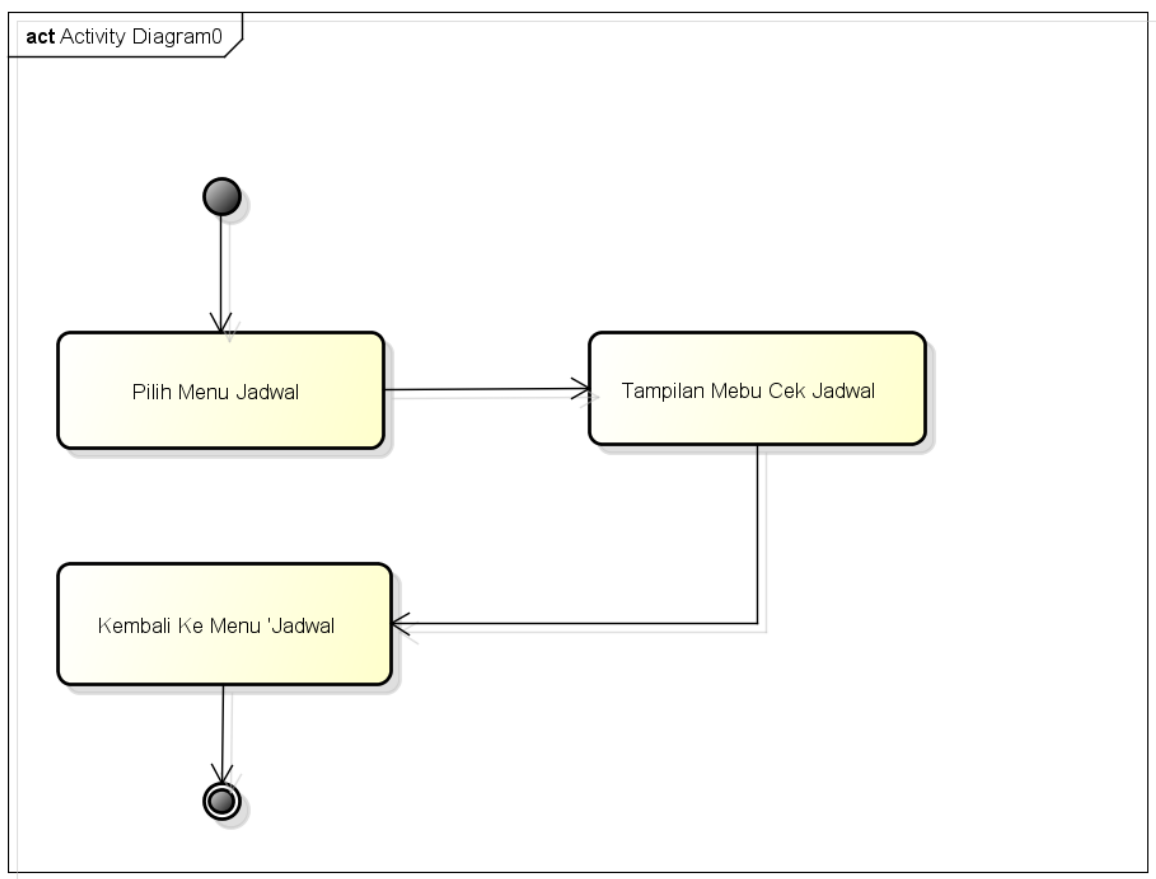

powered by Astah

Gambar 4.3.1.2.3 Diagram Activity Cek jadwal 


\subsubsection{Sequence Diagram}

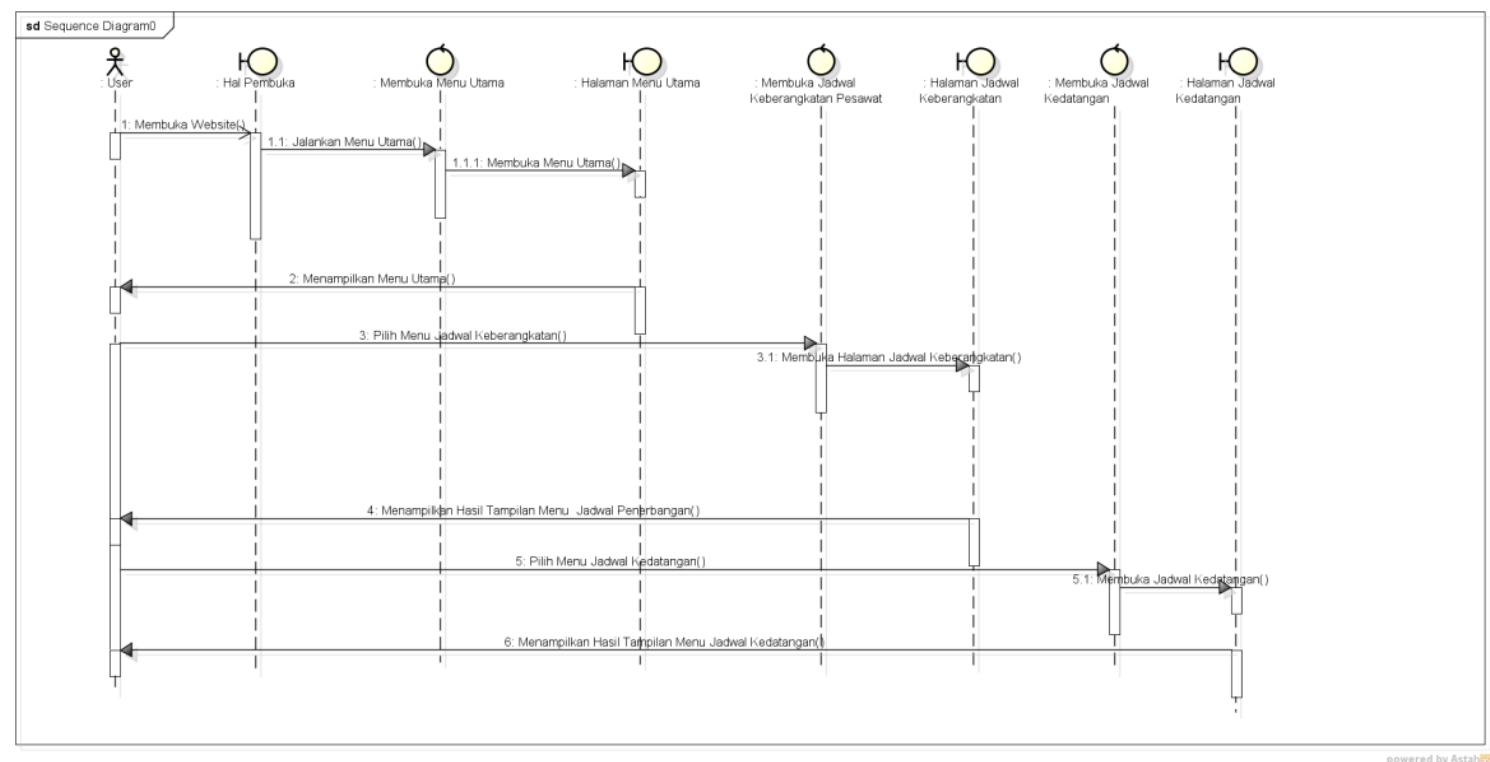

Gambar 4.3.1.3 Sequence Diagram

\subsection{Implementasi Antar Muka}

\subsubsection{Dokumen Tampilan Menu Program}

Tampilan atau halaman-halaman yang terdapat di dalam sistem informasi jadwal penerbangan pesawat seperti di bawah ini :

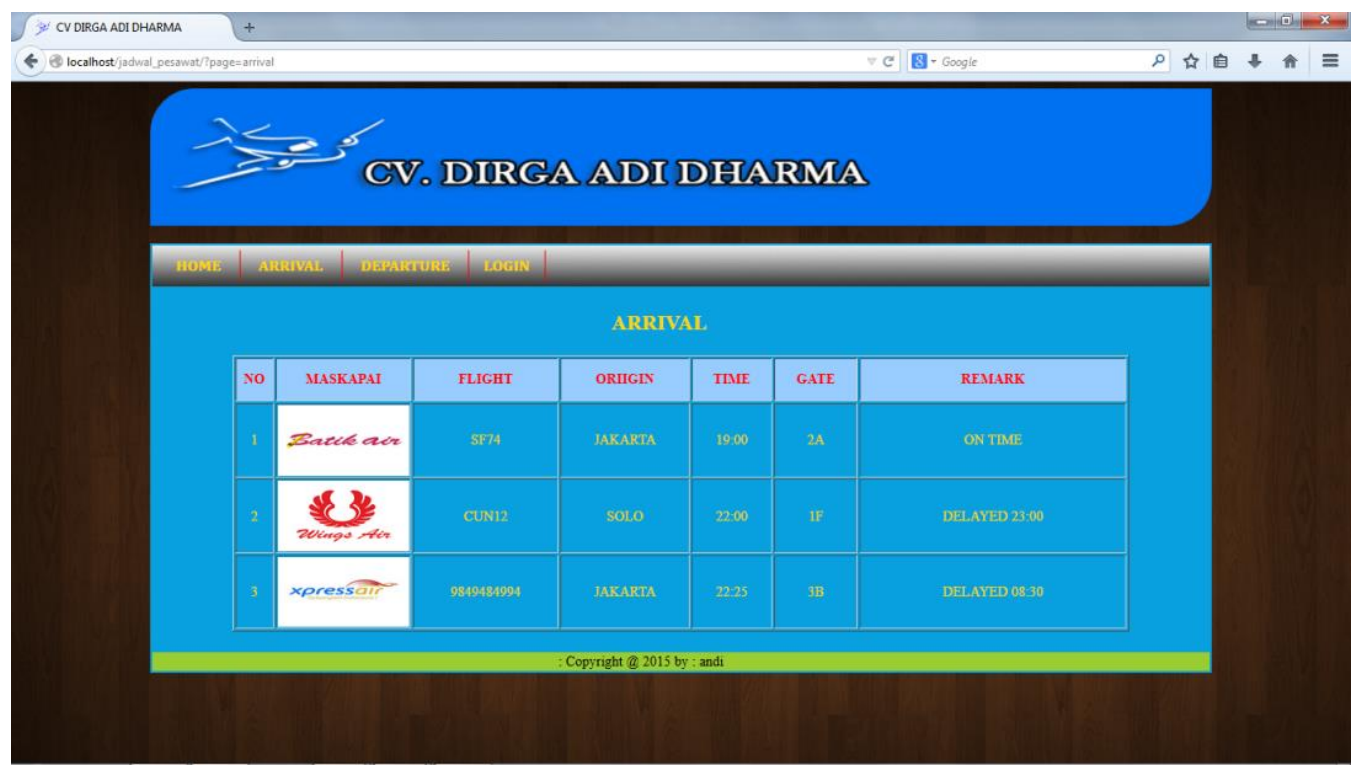

Gambar 4.4.1 Tampilan Menu Utama

Pada tampilan menu utama diatas tentang informasi jadwal penerbangan pesawat yang di informasikan, Profil, user dapat memilih informasi penerbangan pesawat dab admin dapat masuk ke 
menu login untuk memperbaharui informasi jadwal penerbangan pesawat.

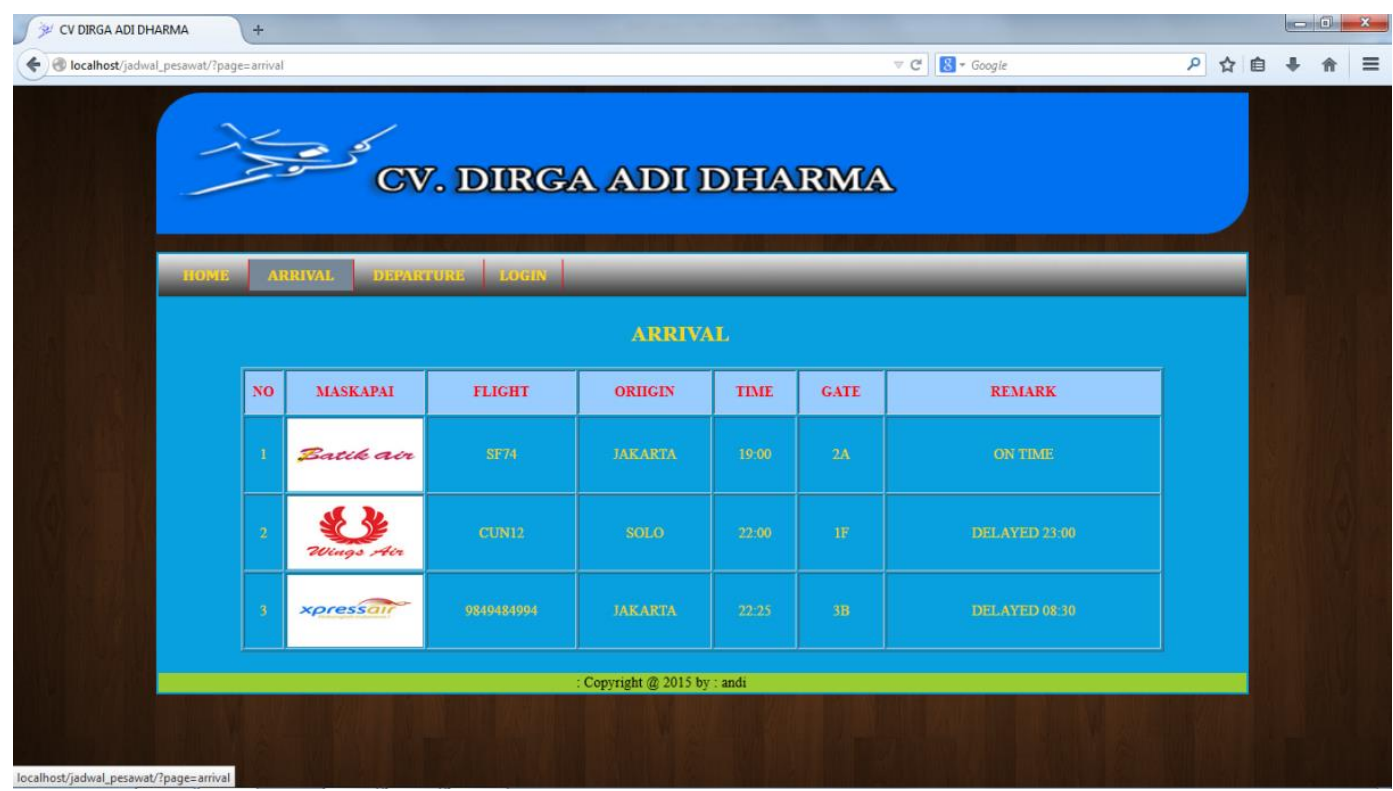

Gambar 4.4.2 Tampilan Menu Arrival

Pada menu arrival user dapat melihat informasi jadwal keberangkatan penerbangan pesawat,di menu arrival user dapat mengetahui nama maskapai pesawat, flight, origin, time, gate dan remark.

\subsubsection{Tampilan Menu Departure}

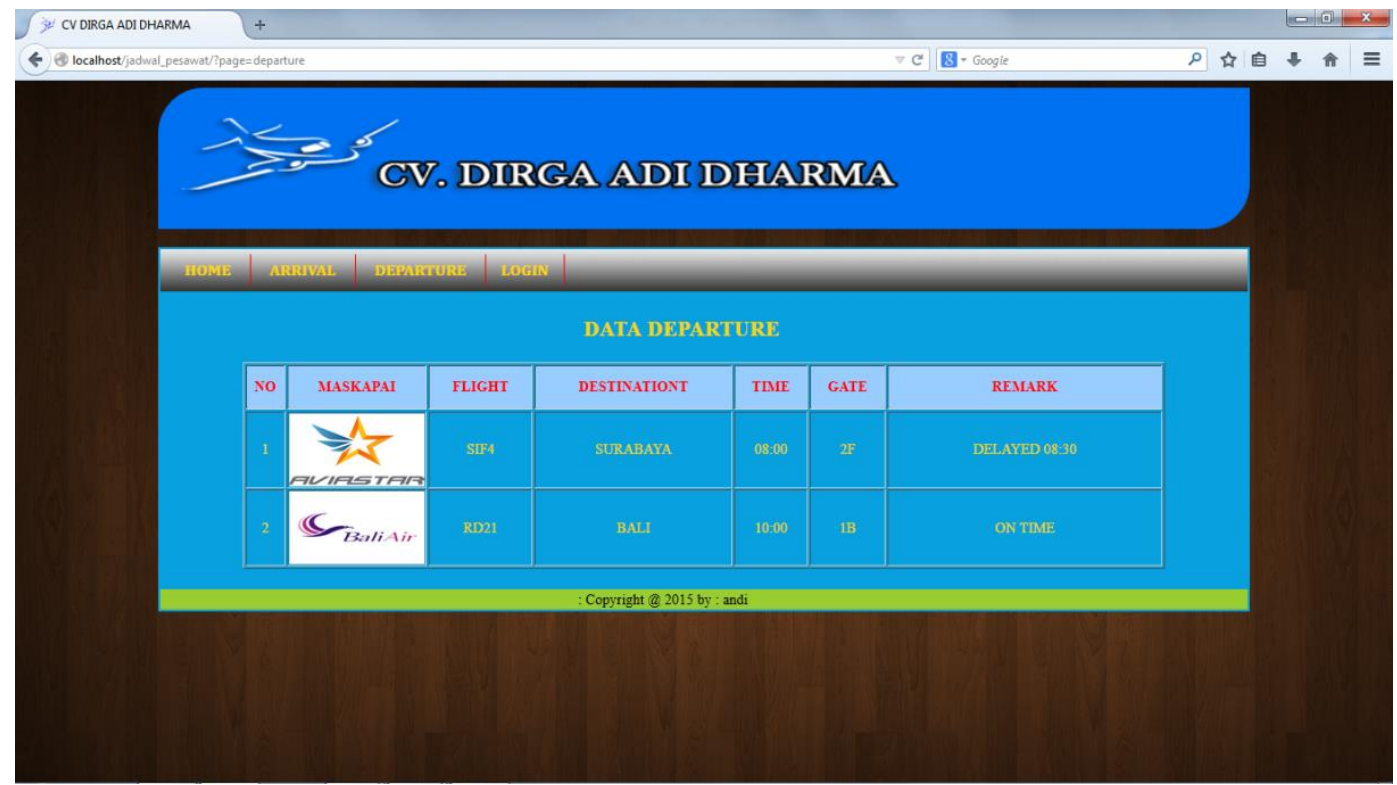

Gambar 4.4.3 Tampilan Menu Departure 
Pada menu departure user dapat melihat informasi jadwal tiba penerbangan pesawat, di menu departure user dapat mengetahui nama maska-

pai pesawat, flight, destination, time, gate dan remark.

\subsubsection{Tampilan Login}

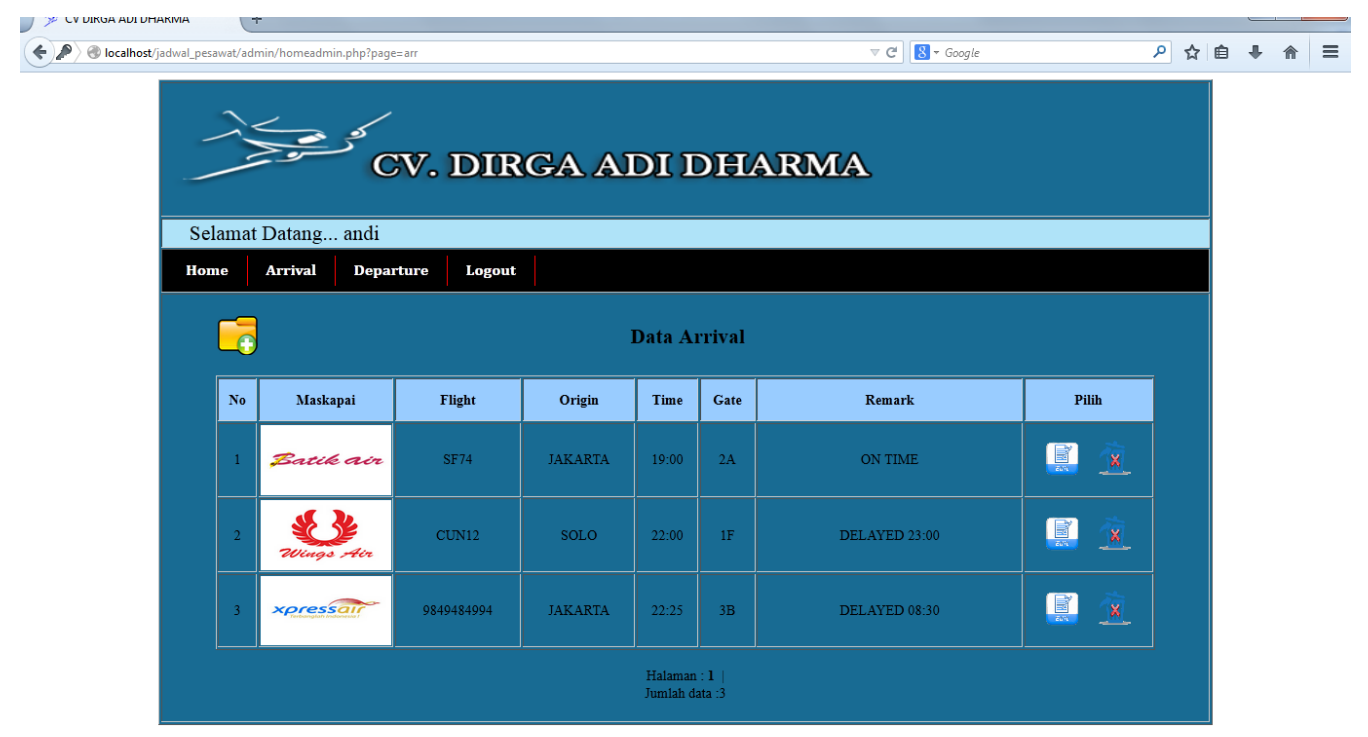

Pada menu login admin dapat memperbaharui informasi jadwal keberangakatan penerbangan pesawat dan jadwal tiba penerbangan pesawat, di menu login admin dapat menghapus data yng salah dan mengubah informasi tersebut. Informasi yang akan diperbaharui mengenai maskapai pesawat, flight, origin, destination, time, gate dan remark.

\subsubsection{Tampilan Menu Home Admin}

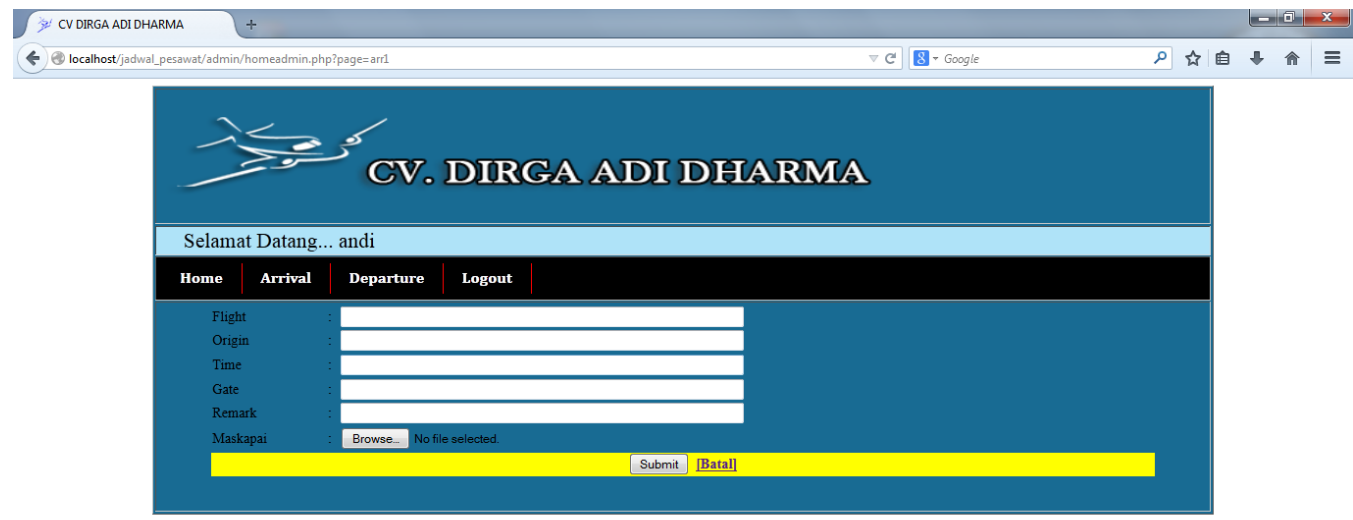


Pada menu home admin, disini admin mengisi form untuk memperbaharui informasi jadwal penerbangan pesawat, pengisian form tersebut terdiri dari flight, origin, time, gate, remark, dan maskapai penerbangan. Setelah selesai mengisi form admindapat memperbaharui informasi jadwal keberangakatan penerbangan pesawat dan jadwal tiba penerbangan pesawat lalu submit.

\section{PENUTUP}

\subsection{Kesimpulan}

Setelah menganalisa permasalahan yang selama ini terjadi pada CV. Dirga Adi Dharma , maka penulis dapat menyimpulkan sebagai berikut:

1. Sistem informasi jadwal penerbangan yang selama berkomputerisasi dimaksudkan untuk meningkatkan efisiensi dan efektifitas kerja dalam pengolahan data, guna memperoleh informasi dengan cepat dan akurat sehingga dapat digunakan sebagai bahan untuk pengambilan keputusan bagi pimpinan dalam menetukan langkah dan tujuan yang dicapai.

2. Penerapan sistem komputerisasi pada sistem informasi jadwal penerbangan pesawat $\mathrm{CV}$. Dirga 'Adi Dharma terhadap pelanggan akan sangat membantu perusahaan dalam memenuhi kebutuhan laporan yang diharapkan.

\subsection{Saran}

Sistem informasi jadwal penerbangan pesawat pada CV. Dirga Adi Dharma yang masih menggunakan sistem manual dalam pembuatan laporan inforasi jadwal penerbangan peswat masih lambat dan kurang akurat. Dengan sistem informasi jadwal penerbangan pesawat yang terkomputerisasi diharapakan dapat mengurangi permsalahan yang selama ini sering dihadapi CV.
Dirga Adi Dharma. Namun untuk menjaga agar sistem yang terkomputerisasi tersebut dapat bekerja dengan baik tentunya diperlukan tenaga yang memiliki kemampuan dibidang komputer agar selalu menjaga sistem tersebut.

\section{DAFTAR PUSTAKA}

Agus Mulyanto. 2009. Sistem Informasi Konsep dan Aplikasi. Pustaka Pelajar.

Al-Bahra bin Ladjamudin. 2005. Analisis dan Desain Sistem Informasi. Graha Ilmu. Yogyakarta

Basuki, AP, 2010. Membangun Web Berbasis PHP dengan Framework Codeigniter. Lokomedia.Yogyakarta

Hidayat,Deddy. 2010. Definisi Sistem. Jurnal Cyber Raharja. Tangerang.

Jogiyanto, Hartono MBA. Ph. D. 2005. Analisa dan Desain Sistem Informasi, C. V Andi Offset. Yogyakarta.

M.Scott, George. 2001. Prinsip-prinsip Sistem Informasi Manajemen, Raja Grafindo Persada. Jakarta.

Ruiz-Mafe, Carla.,Sanz-Blas, Silvia., AldasManzano, Joaquin. 2009. Journal of Air Transport Management ,Drivers and barriers to online airline ticket purchasing www.elsevier.com/locate/jairtraman. Diakses (1 Juli 2015)

Sigiarti, Yuni. 2011. Metode Penelitian Dibidang Komputer Dan Teknologi Informasi. Banten.

Tata, Sutabri. 2012. Analisis Sistem Informasi. Andi Offset. Yogyakarta.

Utari, Woro. 2010. Jurnal Mitra Ekonomi dan Manajemen Bisnis, Vol.1, No. 2, Oktober 2010 https://docs.google.com/document/d/1JlLn hQTsMinNpMidOZfEWwcfSOLllZXhAu7Es MXL3Yo/preview. Diakses (4 Juli 2015) 